\title{
Analisis Jaringan Sosial Bursa Jual Beli Facebook di Kepulauan Riau
}

\author{
Firmansyah Kusasi, Iranita \\ Fakultas Ekonomi,Universitas Maritim Raja Ali Haji, Tanjungpinang, Kepulauan Riau Indonesia
}

\begin{abstract}
ABSTRAK : Provinsi Kepulauan Riau memiliki potensi UMKM yang besar, namun dengan keadaan geografisnya yang 95\% terdiri dari lautan, dengan jumlah pulau berpenghuni hanya 394 dari 1.796 yang tersebar merata menjadikannya disadvantage bagi mereka dalam memasarkan produknya. Oleh karena itu teknologi sistem informasi bisa memberikan solusinya, seperti e-commerce dalam bentuk pemasaran melalui jaringan sosial media. Namun belum ada data yang menggambarkan bentuk jaringan pemasaran online dan efektifitas pemasaran online bagi UMKM di Provinsi Kepri. Penelitian ini menggunakan pendekatan Analisis Jaringan Sosial, untuk melihat implementasi e-commerce dalam bentuk pemasaran dan perdagangan online melalui jaringan sosial. Kami menemukan bahwa: 1. Bentuk pola jaringan marketing dan jual-beli online (e-commerce) oleh UMKM yang terdapat di Provinsi Kepulauan Riau masih terpusat pada kota dan kabupaten yang sudah lebih dahulu berkembang dan memiliki akses yang lebih baik untuk melakukan jual beli online. Baik dalam arti fasilitas mauapun letak geografis dan tingkatan ekonominya; 2. Karakteristik jaringan jual-beli online di Provinsi Kepulauan Riau masih bersifat kedaerahan. Artinya jaringan masih terkumpul pada kota dan kabupaten bersangkutan. Walaupun dijumpai beberapa node juga memiliki jaingan lebih dari satu BJB.; 3. Hubungan antar BJB di kepri masih bersifat sentral, dan belum menyebar.; 4. Faktor-faktor yang mendukung berkembangnya pemasaran online di kepri adalah fasilitas internet yang baik dan adanya standarisasi produk. Saran kami bagi pemerintah daerah adalah agar lebih meningkatkan fasilitas jaringan online dan mensosialisasi dan meningkatkan pengetahuan para penggiat UMKM untuk lebih focus pada pemasaran online. Tentu ini memerlukan dukungan dari pihak pemerintah daerah masing-masing.
\end{abstract}

Kata kunci: Analisis Jaringan Sosial, Bursa Jual Beli, Media Sosial, jual-beli online

Email Address : fkusasi@umrah.ac.id , iranita27@gmail.com

\section{Pendahuluan}

Permasalahan mendasar yang sering dihadapi pemilik UMKM sebenarnya adalah lemahnya penetrasi pasar dan kurang luasnya jangkauan wilayah pemasaran. Banyak kasus UMKM di Indonesia yang tidak dapat melakukan strategi pemasaran yang tepat. Cenderung UMKM di Indonesia hanya "menunggu konsumen" dan monoton dalam melakukan kegiatan pemasaran. Menurut Dr. Ina Primiana dalam bukunya Menggerakan Sektor Riil UKM \& Industri (Primiana, 2009), selain permodalan, yang menjadi pokok permasalahan bagi UMKM berkaitan dengan pemasaran, seperti: 1. sulitnya akses pasar dikarenakan keterbatasan-keterbatasan antara lain membaca selera pasar, mengenal pesaing dan produknya, memposisikan produknya di pasar, mengenal kelemahan produknya diantara produk pesaing; 2. Keterbatasan SDM. Untuk usaha Mikro dan Kecil pada umumnya pemilik masih melakukan semua kegiatan sendiri atau dibantu beberapa pegawai seperti produksi atau pengawasan produksi, sehingga mencari pasar menjadi terbengkalai; 3. Strandarisasi produk lemah, hal ini menyebabkan pesanan dikembalikan (retur) dikarenakan kualitas produk yang dihasilkan spesifiknya tidak sesuai dengan pada saat pesan; dan 4. Hilangnya kepercayaan pelanggan akibat ketidakmampuan memenuhi permintaan dalam jumlah besar, antara lain dikarenakan tidak 
tersedianya dana untuk memenuhi permintaan tersebut. Sebagai tambahan, untuk kawasan kepulauan seperti provinsi Kepulauan Riau, maka kondisi geografis yang terdiri dari pulaupulau yang menyebar merata di lautan yang meliputi $94 \%$ dari luas wilayah juga bias menjadi penghalang atau kendala bagi penggiat UMKM dalam memasarkan dan menjual produknya.

Di sinilah teknologi dapat membantu meringankan masalah yang dihadapai penggiat UMKM. Seiring dengan semakin berkembangnya teknologi informasi dan komunikasi seperti internet, dengan harga yang terjangkau, maka internet semakin mudah diakses untuk segala kebutuhan. Termasuklah dimanfaatkan sebagai ajang promosi dan transaksi jual-beli yang efektif. Mulai dari pengusaha kecil, menengah, hingga perusahaan besar menggunakan media internet untuk menjangkau pasar yang lebih luas. Pola ini disebut dengan e-commerce (perdagangan secara elektronik). Dengan memanfaatkan e-commerce, bisnis memiliki peluang untuk menjangkau pasar yang luas bahkan global. E-commerce dalam dunia bisnis dapat mendukung pemotongan rantai distribusi, sehingga konsumen dapat memperoleh suatu produk dengan harga murah. Selain itu, pemasaran produk dengan ecommerce memiliki beberapa manfaat antara lain, informasi yang tepat sasaran, biaya yang murah dan efisien, yang memberikan akses tanpa batas kapan saja di mana saja.

Bahkan perkembangan terkini di bidang teknologi mobile berupa smartphone, tablet, dan ultrabook, ditambah keluasan daerah cakupan jaringan internet kecepatan tinggi (jaringan internet 4G LTE), disertai dengan kemajuan dibidang web-programming dan mobile OS dan dukungan sistem logistik jasa kurir pengiriman barang, maka terbentuklah pola baru pemasaran dan perdagangan elektronik yang selama ini dilakukan melalui dekstop kini sudah bisa dilakukan secara mobile, atau disebut juga mobile e-commerce.

Beberapa faktor tambahan yang
mendukung e-commerce antara lain:

pulau, ketersediaan jasa kurir, ketersediaan jasa keuangan di pelosok pulau (walaupun hal ini bisa diatasi dengan mobile banking selama ada jaringan internet), dan ketersediaan SDM yang mengerti dalam mengelola e-commerce, baik itu melalui situs web blog, online shopping termediasi, maupun jaringan sosial media.

Namun demikian, perkembangan terkini dalam bidang e-commerce dalam bentuk pemasasan online di Provinsi Kepulauan Riau belum diketahui bentuk dan polanya. Belum terdapat data yang menggambarkan peran ecommerce dalam meningkatkan pertumbuhan UMKM Kepri, seberapa besar efektifitasnya, dan apakah faktor-faktor yang mendukung dan apakah yang melemahkannya. Dengan mengetahui karakteristik pola jaringan ecommerce dan faktor-faktor pendukungnya maka diharapkan informasi ini dapat digunakan sebagai bahan pertimbangan dalam membuat satu kebijakan guna meningkatkan efektifitas praktek e-commerce-terutama pemasaran online - dalam meningkatkan keberhasilan pertumbuhan UMKM di provinsi Kepulauan Riau.

Oleh karena itu, pada penelitian ini kami ingin memetakan bentuk jaringan dari pemasaran online UMKM Kepri (baik melalui web blog maupun online shop) dan bursa jual beli melalui media sosial (facebook, twitter, BBM). Dimana analisis yang digunakan adalah Analisis Jaringan Sosial (Social Network Analysis-SNA). Analisis ini digunakan karena ia dapat menginvestigasi karakteristik kuantitatif struktur jaringan yang tak terdapat pada kajian karakteristik individu atau kajian hubungan sederhana. Fokus dari analisis jaringan ini adalah untuk memahami bagaimana karakteristik struktur dari sebuah jaringan dapat mempengaruhi perilaku. Dari analisis ini akan diperoleh informasi karakteristik anggota jaringan seperti ukuran jaringan, kekerapan interaksi, atau kekuatan hubungan, yang berguna untuk menentukan bagaimana struktrur sebuah jaringan mempengaruhi anggotanya. Informasi ini diperlukan dalam menginvestigasi beberapa isu bersifat struktural diantaranya: apakah jaringan 
terpusat/tak terpusat mendorong kepercayaan antar anggota, atau seberapa besar pengaruh suatu kelompok dalam jaringan yang padat vs jaringan yang renggang, atau apakah pengguna ujung-pangkal diposisikan dalam inti jaringan ataukah tepi jaringan, dengan mengambil data pada hubungan langsung dan tidak langsung yang memberikan kesempatan dan hambatan yang berbeda bagi tiap anggota jaringan.

\section{Tujuan penelitian}

Penelitian ini bertujuan untuk mengetahui bentuk pola jaringan marketing dan jual-beli online (e-commerce) oleh UMKM yang terdapat di provinsi Kepulauan Riau; untuk mengetahui karakteristik anggota jaringan marketing dan jual-beli online (e-commerce) oleh UMKM yang terdapat di provinsi Kepulauan Riau; untuk mengetahui bentuk hubungan antar anggota jaringan marketing dan jual-beli online (e-commerce) oleh UMKM yang terdapat di provinsi Kepulauan Riau; untuk mengidentifikasi faktor-faktor yang mendukung marketing dan jual-beli online (e-commerce) oleh UMKM yang terdapat di provinsi Kepulauan Riau; dan dalam rangka mengidentifikasi faktor-faktor yang melemahkan marketing dan jual-beli online (e-commerce) oleh UMKM yang terdapat di provinsi Kepulauan Riau.

\section{Telaah Pustaka}

\section{Perdagangan Elektronik}

Yang dimaksud dengan Perdagangan elektronik bukanlah perdagangan barang-barang elektronik, melainkan transaksi perdagangan yang dilakukan secara elektronik. Perdagangan elektronik (bahasa Inggris: electronic commerce atau e-commerce) adalah kegiatan-kegiatan bisnis yang melibatkan konsumen (consumers), pembuat barang (manufactures), service providers dan pedagang perantara (intermediaries) dengan menggunakan jaringanjaringan komputer yaitu internet. E-commerce juga meliputi penyebaran, pembelian, penjualan, pemasaran barang dan jasa melalui sistem elektronik seperti internet atau televisi, internet, atau jaringan komputer lainnya. E-commerce dapat melibatkan transfer dana elektronik, pertukaran data elektronik, sistem manajemen inventori otomatis, dan sistem pengumpulan data otomatis.

Julian Ding dalam bukunya Ecommerce: Law \& Practice, (Ding, 1999) mengemukakan bahwa e-commerce sebagai suatu konsep yang tidak dapat didefinisikan. Ecommerce memiliki arti yang berbeda bagi orang yang berbeda. Sedangkan Onno W. Purbo dan Aang Wahyudi yang mengutip pendapatnya David Baum, menyebutkan bahwa: "e-commerce merupakan suatu set dinamis teknologi, aplikasi dan proses bisnis yang menghubungkan perusahaan, konsumen dan komunitas melalui transaksi elektronik dan perdagangan barang, pelayanan dan informasi yang dilakukan secara elektronik."

Industri teknologi informasi melihat kegiatan e-commerce ini sebagai aplikasi dan penerapan dari e-bisnis yang berkaitan dengan transaksi komersial, seperti: transfer dana secara elektronik, SCM (supply chain management), pemasaran elektronik (e-marketing), atau pemasaran online (online marketing), pemrosesan transaksi online (online transaction processing), pertukaran data elektronik (electronic data interchange /EDI), dll. Ecommerce digunakan sebagai transaksi bisnis antara perusahaan yang satu dengan perusahaan yang lain (B2B), antara perusahaan dengan pelanggan (B2C), atau antara perusahaan dengan institusi yang bergerak dalam pelayanan public (B2G).

\section{Bentuk e-commerce}

Beberapa bentuk e-commerce yang berkembang dalam mendukung perdagangan dan bisnis UMKM antara lain adalah sebagai berikut:

1. E-commerce berbasis BJB (bursa jual beli) online, umumnya berbasis media sosial seperti KasKus, facebook, IG, BBM, Whatsapp, dan twitter; disini proses perdagangan terjadi antara customer to customer $(\mathrm{C} 2 \mathrm{C})$ yang transaksinya bersifat sporadis dan dapat dilakukan secara 
langsung maupun melalui rekening bersama. Dalam BJB, pemasaran barang murni semata-mata diviralkan melalui media sosial, di mana promosi dibantu oleh feature notifikasi dan search engine yang disediakan oleh aplikasi media sosial tersebut.

2. E-commerce berbasis Online shop, dimana website sebagai virtual gallery yang menarik dan terstruktur ditambah dengan berbagai skim promosi. Disini admin situs online shopping menyediakan lapak maya bagi para penjual. Selain itu admin juga mengelola transaksi agar aman dari penipuan dengan menyediakan akun rekening baik bagi pembeli dan penjual. Online shop ini juga membantu menginkalankan barang secara progresif menggunakan metode content marketing selain feature search engine. Contoh online shopping antara lain: Lazada, bukalapak.com, Tokopedia, Matahari Mall, Zalora, Berry Benka, Shopee dll.

3. E-commerce berbasis web blog, dimana pemilik usaha masarkan dan menjual barang atau jasanya secara online melalui situs web blog. Situs web blog digunakan karena situs ini memiliki feature SEO (search engine optimization). Yaitu suatu feature yang membuat suatu situs selalu terletak di daftar paling atas hasil pencarian menggunakan search engine seperti Google, Yahoo, bing, dll. Dalam hal ini pemilik situs harus bisa mengelola situs secara mandiri dan mendesain situs yang menarik, disamping harus menyediakan menu testimoni agar meyakinkan pembeli bahwa situs itu bukan penipuan. Pada pola ini transaksi terjadi tanpa mediasi pihak lain sebagaimana pada online shopping. Oleh karena itu pemilik situs harus menyediakan akun banknya untuk keperluan transaksi jual-beli, atau memanfaatkan akun rekber (rekening bersama) seperti pada BJB.

\section{Analisis Jaringan Sosial}

Analisis jaringan sosial (SNA) telah menjadi salah satu topik paling menarik bagi para peneliti untuk menganalisis dan menjelajahi dunia di dalam jaringan. Konsep SNA membantu peneliti untuk mempelajari jaringan sosial untuk pemahaman yang lebih baik tentang struktur jaringan, perilaku aktor dan hubungan antara aktor dalam suatu jaringan (Nor Amalina Abdul Rahim dan Sarina Sulaiman, 2015). Jaringan adalah sekelompok struktur sosial yang terdiri dari simpul-simpul di mana beberapa simpul terhubung satu sama lain oleh tautan atau disebut juga sebagai tepi atau ikatan. Node dalam jaringan adalah aktor sementara tautan menunjukkan hubungan atau koneksi antar node (Zeng, dkk. 2011).

SNA tidak hanya berfokus pada jejaring sosial, tetapi juga fokus pada bidang lain seperti pemasaran, bisnis, medis, pendidikan, struktur komunitas dan banyak lagi. Melalui SNA, aktoraktor penting, kaitan penting dan perilaku jaringan dapat ditentukan, dan pertanyaanpertanyaan yang bermakna tentang struktur hubungan dapat dijawab. SNA menganggap bahwa hubungan itu penting (Nor Amalina Abdul Rahim dan Sarina Sulaiman, 2015). Zhu dkk. (2009) mendefinisikan SNA sebagai pemetaan dan pengukuran hubungan dan arus antara orang, tim, organisasi, komputer, situs web, dan informasi lainnya atau entitas pemrosesan pengetahuan. Pada awal tahun 1970an, SNA menjadi jauh lebih populer dengan para peneliti ketika perbaikan dalam teknologi komputer memungkinkan untuk mempelajari kelompok besar. SNA yang terdiri dalam menghasilkan pola yang memungkinkan mengidentifikasi interaksi yang mendasari antara pengguna platform yang berbeda, telah menjadi bidang dampak tinggi sejak tahun lalu (Palazuelos dkk. 2013).

Hasil analisis jaringan sosial dapat digunakan untuk mengidentifikasi individu, tim, dan unit penting yang memainkan peran utama, untuk mencari peluang untuk mempercepat arus pengetahuan melintasi batas-batas fungsional dan organisasi, untuk memperkuat efisiensi dan efektivitas dari formal yang sudah ada. saluran komunikasi, untuk meningkatkan kesadaran dan refleksi tentang pentingnya jaringan informal dan cara-cara untuk meningkatkan kinerja 
organisasi mereka dan untuk meningkatkan inovasi dan pembelajaran.

Analisis Jaringan Sosial bertujuan menyelidiki struktur sosial dengan penggunaan teori jaringan dan grafik (Otte dan Ronald, 2002). Analisis ini menggambarkan karakter struktur jaringan dalam hal node (aktor individu, orang, atau hal-hal dalam jaringan) dan hubungan, pojokan, atau link (hubungan atau interaksi) yang menghubungkan mereka. Contoh struktur sosial yang umumnya divisualisasikan melalui analisis jaringan sosial termasuk jaringan media sosial, (Grandjean ,2016), meme yang tersebar, jaringan pertemanan dan kenalan, grafik kolaborasi, kekerabatan, transmisi penyakit, dan bahkan hubungan seksual. Jaringan ini sering divisualisasikan melalui sosiogram di mana node direpresentasikan sebagai titik dan ikatan direpresentasikan sebagai garis. (D'Andrea, 2009; dan Pinheiro, 2011).

Penelitian mengenai SNA (Social Network Analysis) sebenarnya sudah dimulai puluhan tahun yang lalu, jauh sebelum era media sosial seperti Facebook dan Twitter. Analisa jaringan sosial merupakan suatu teknik untuk memetakan dan mengukur relasi dan komunikasi yang terjadi antar manusia, kelompok, organisasi, komputer ataupun entitas yang memproses suatu informasi (Charu, 2011). Namun dalam beberapa tahun terakhir sejumlah alat SNA telah dikembangkan seperti Pajek, ORA, UCINET, NodeXL, NetDriller dan banyak lagi. Alat-alat ini menunjukkan jaringan divisualisasikan kepada pengguna dan pengguna dapat menggunakan fungsi yang disediakan untuk melakukan beberapa analisis umum pada jaringan (Koochakzadeh dkk. 2011).

Banyak istilah teori graf yang dipakai pada analisis jaringan sosial. Node pada teori graf bisa dilambangkan sebagai individu, kelompok atau komunitas, sedangkan edge sebagai hubungan antar individu. Misalnya terdapat edge antara node $\mathrm{A}$ dan node $\mathrm{B}$, berarti mereka sudah saling berhubungan. Edge tersebut memiliki bobot yang digunakan sebagai ukuran dalam analisis jaringan sosial. Ukuran hubungan antara dua node digambarkan sebagai bobot hubungan, yang bisa merupakan kekerapan interaksi, kedekatan, tingkat permusuhan, prestige, tingkat kecintaan, dan sebagainya.

Hubungan relasi ini divisualisasikan dengan graph SNA (selanjutnya disebut sociogram) yang tervisualisasi sehingga menjadi lebih mudah untuk dianalisis. Hubungan relasi ini divisualisasikan dengan graph dimana pada gambar yang disebut node atau simpul merepresentasikan personal atau individu yang dihubungkan oleh garis yang membentuk vertex. Dua node yang terhubung dinyatakan dengan adanya garis yang menghubungkan keduanya.

Node dan vertex memiliki arti pengukuran tersendiri yang dijelaskan oleh beberapa terminologi dalam teori graf berikut ini

a) Degree centrality, yaitu jumlah koneksi yang dimiliki sebuah node.

b) Closeness centrality, yaitu jarak rata-rata antara suatu node dengan semua node lain di jaringan, sehingga ukuran ini menggambarkan kedekatan node ini dengan node lain. Semakin dekat, semakin terhubung orang tersebut dengan lainnya.

c) Betweenness centrality, dihitung dengan menjumlahkan semua jalur terdekat yang mengandung node tersebut. Pengukuran ini memperlihatkan peran sebuah node menjadi bottleneck. Node menjadi penting jika menjadi jalur sempit komunikasi. Anggaplah persimpangan sebagai node, maka semakin banyak jalan yang harus melewati persimpangan itu (misal tidak ada jalan alternatif), artinya semakin penting arti persimpangan tersebut.

d) Eigenvector centrality, yaitu pengukuran yang memberikan bobot yang lebih tinggi pada node yang terhubung dengan node yang juga memiliki keterhubungan tinggi. Dapat juga dikatakan versi rekursif dari degree centrality.

e) PageRank, yaitu suatu pengukuran yang lazim digunakan Google untuk menentukan kualitas suatu page. Dapat digunakan untuk jaringan yang berbentuk graph berarah. Prinsip yang digunakan adalah semakin penting sebuah node, maka semakin banyak 
node tersebut dirujuk oleh node lain.

f) Clustering coefficient, yang menghitung proporsi keterhubungan node di dalam kelompok. Semakin kuat ikatan kelompok (semakin tinggi clustering coefficient) maka semakin terhubung satu sama lain node-node di dalam kelompok tersebut.

Untuk melakukan analisis jaringan sosial dapat dilakukan dengan perhitungan secara matematika. Namun apabila aktor yang dilibatkan dalam suatu jaringan sangat banyak, perhitungan ini dapat dilakukan dengan menggunakan bantuan perangkat lunak (software), dalam hal ini Gephi ver. 8.0. Secara spesifik, analisis jaringan sosial mempelajari berbagai macam hubungan antar individu. Hubungan tersebut antara lain keantaraan (betweenness), sentralitas (centrality), kedekatan (closeness), derajat (degree), sentralitas vektor eigen (eigenvector centrality), jarak (range), konektivitas (connectivity), dan bentuk jaringan bintang (star).

Pada analisis jaringan sosial, graf digunakan terutama dalam visualisasi data yang telah diperoleh melalui analisis tersebut. Dalam visualisasi graf, terdapat tiga hal yang penting yaitu himpunan simpul (node), himpunan sisi (edge), dan informasi-informasi tambahan mengenai simpul-simpul dan sisi-sisi tersebut termasuk informasi lokasi geografis. Visualisasi melalui graf ini sudah banyak dilakukan sejak lama. Para anthropologist dan sociologist sering menggunakan graf dalam analisis jaringan sosial untuk menyelesaikan masalah sosial tertentu.

Dalam visualisasi jaringan sosial menggunakan graf, saat ini banyak aplikasi yang dapat digunakan. Dengan aplikasi - aplikasi tersebut, pengguna dapat dengan mudah memvisualisasikan dalam bentuk graf. Input yang diperlukan untuk aplikasi tersebut biasanya berupa data-data yang telah kita peroleh. Contoh aplikasi tersebut diantaranya Centrifuge, Commetrix, NodeXL, Agna dan Gephi. Berikut contoh bentuk analsis graf dari jaringan sosial.

\section{Penelitian Terdahulu}

Beberapa penelitian telah dibuat dalam mengkaji masalah pemasaran online oleh UMKM. Diantaranya adalah Setiawati dan Widyartati (2017) yang meneliti bagaimana Pengaruh Startegi Pemasaran online terhadap Peningkatan Laba UMKM. Septyato dan Dewanto (2016) membuat model strategi eMarketing UMKM di Indonesia dengan asusmsi perkembangan internet dapat memperbaiki cara melakukan bisnis dari tradisional ke elektronik yang mengarah ke pemasaran elektronik. Supriyati dan Iqbal (2013), meneliti UMKM di Kab Kudus yang bergerak di bidang konveksi dan kerajinan bordir. Priambada (2015) melakukan penelitian untuk mengidentifikasi penggunaan media sosial dan manfaatnya pada UKM di wilayah Malang Raya dan Surabaya. Hasil penelitian menunjukkan bahwa media sosial yang paling banyak digunakan adalah website, Facebook dan E-mail. Öztamur, Dilhan., dan İbrahim Sarper Karakadilar, (2014), menemukan bahwa media sosial bukan hanya alat komunikasi untuk hiburan, tetapi juga merupakan bagian penting dari strategi pemasaran dalam kehidupan bisnis.

\section{Metode Penelitian}

Penelitian ini dilaksanakan dengan menggunakan metode exploratory research diharapkan dapat memberikan informasi tentang pemetaan jaringan pemasaran dan jual-beli online oleh pelaku UMKM di provinsi Kepulauan Riau. Analisa dilakukan dalam dua tahap, pertama adalah analisa diskriptif dari profil UMKM yang diteliti dan kedua analisis jaringan sosial atau SNA yang diterapkan untuk menentukan hubungan penggiat UMKM dengan pasar dan jaringan lain yang mendukung, seperti supplier, bank, distributor. Metodologi dari penelitian ini dibagi dalam desain penelitian dan subyek penelitian, metode pengumpulan data dan metode analisis data.

\section{Desain Penelitian}

Desain penelitian ini menggunakan metode penelitian kuantitatif, yang menguji teori - teori tertentu dengan cara meneliti hubungan antarvariabel. Variabel - variabel ini di ukur 
dengan instrument - instrument penelitian, sehingga data yang terdiri dari angka -angka dapat di analisis berdasarkan prosedur - prosedur statistik (Creswell, 2013). Unit analisis dalam penelitian ini adalah perusahaan jasa, dagang dan manufaktur yang bersakala UMKM atau Usaha Mikro Kecil dan Menengah, dengan lokasi pengambilan sample di wilayah Provinsi Kepulauan Riau, yang telah menggunakan metode pemasaran online.

Sumber data yang berhubungan dengan penelitian ini berasal dari sumber data primer dan data sekunder. Sumber data primer dalam penelitian ini diperoleh dengan mengirimkan kuesioner permohonan kepada responden, sesuai dengan topik dalam penelitian ini, melalui surat elektronik (surel) dan inbox message.

\section{Pengumpulan Data}

Penelitian ini menggunakan data primer yang diperoleh berdasarkan pertanyaan melalui kuesioner kepada pemilik/pengelola UKM. Data yang diperoleh meliputi data karakteristik umum, data penggunaan sosial media dalam perusahaan, termasuk tujuan, manfaat dan hambatan yang dihadapi. Data dilengkapi dengan hasil observasi peneliti terhadap UKM dan media sosial yang digunakan.

\section{Populasi dan Sampel}

Populasi dalam penelitian ini seluruh pelaku UMKM di provinsi Kepulauan Riau. Adapun cara pengambilan sampel dalam penelitian ini adalah dengan cara purposive sampling. Sample diambil dari Grup BJB yang paling banyak anggotanya di Kota atau Kabupaten di Kepri. Dari semua Anggota diambil sampel sebanyak $10 \%$ dari jumlah anggota BJB grup FB tersebut. Berikut ini hasil analsa SNA dari jaringan grup BJB Kepri yang menggunakan media sosial Facebook. Lokasi penelitian ini adalah di kota dan kabupaten di provinsi Kepulauan Riau, antaranya kota Batam, Tanjungpinang, Kabupaten Bintan, Karimun, Lingga, Anambas, dan Natuna.

\section{Teknik Analisis}

Teknik analisis data dalam penelitian ini melibatkan pengumpulan data yang didasarkan pada pertanyaan - pertanyaan yang terdapat di dalam kuesioner serta analisis informasi dari para partisipan, yakni responden yang menjadi sampel dalam penelitian ini.

Penelitian ini merupakan penelitian deskriptif observasional pada Usaha Kecil Menengah (UKM) di wilayah Provinsi Kepulauan Riau. Penelitian ini menggunakan metode triangulasi, yang menggabungkan metode wawancara terstruktur, wawancara mendalam dan observasi terhadap UKM dan media sosial yang digunakan. Subyek dalam penelitian ini adalah pemilik atau pengelola UKM yang dipilih secara purposive sampling. Subyek dipilih sesuai dengan kriteria: 1) merupakan pemilik atau pengelola UKM, 2) pernah menggunakan media sosial dalam komunikasi perusahaan, 3) bersedia menjadi subyek penelitian. Total subyek yang direkrut dalam penelitian sebanyak 15 UKM.

Penelitian ini juga menganalisa Jaringan Sosial dari para pelaku UMKM dalam menjalankan usahanya. Untuk menjelaskan proses ini, para peneliti telah mengembangkan kerangka kerja yang menciptakan dasar umum untuk melakukan analisis media sosial. Aral dkk. (2013) menjelaskan peluang penelitian analitik media sosial dan mengusulkan kerangka penelitian untuk memahami hubungan antara masyarakat, bisnis, dan media sosial. Kerangka kerja mereka terdiri dari empat jenis kegiatan yang terkait dengan media sosial, dan tiga tingkat analisis yang dapat dipusatkan oleh peneliti ketika memeriksa kegiatan ini. Demikian pula, dalam tinjauan literatur pada organisasi media sosial (Van Osch \& Coursaris, 2013), Van Osch dan Coursaris mengklasifikasikan studi yang relevan sesuai dengan artefak, aktor dan aktivitas yang mereka periksa.

Namun, beberapa artikel penelitian mempertimbangkan langkah-langkah analitik media sosial. Kerangka semacam itu mengambil bentuk model proses. Fan dan Gordon (2014) mengusulkan proses untuk analitik media sosial yang terdiri dari tiga langkah "menangkap", "memahami", dan "menyajikan". Para penulis 
menyatakan bahwa langkah penangkapan terdiri dari pengumpulan data dan preprocessing itu, sedangkan informasi yang bersangkutan diekstraksi dari data dalam langkah ini. Setelah itu, informasi berisik, jika ada dalam data, harus dihapus. Namun, inti dari langkah ini terdiri dari menerapkan teknik kunci, seperti analisis sentimen atau analisis jejaring sosial, untuk memahami data. Pada langkah terakhir, temuan harus dirangkum dan disajikan (Fan \& Gordon, 2014). Stieglitz dkk. (2014) juga mengusulkan kerangka kerja untuk analitik media sosial (SMA), yang merupakan salah satu yang paling diterima dalam sistem informasi, berdasarkan kutipan dari makalah dalam literatur.

Penelitian ini mengadaptasi kerangka kerja mereka, menambahkan fase penemuan yang datang sebelum fase pelacakan, untuk alasan berikut. Kerangka ini awalnya dikembangkan dalam konteks komunikasi politik. Pada prinsipnya, itu dapat dengan mudah diadaptasi untuk domain penelitian lainnya. Tujuan dan metode analisis mungkin berbeda, tetapi prosesnya pada dasarnya sama. Para peneliti masih perlu mengambil keputusan yang sama mengenai sumber data, pendekatan, arsitektur perangkat lunak dan penyimpanan data. Dalam politik, sering diketahui sebelumnya topik mana yang harus dilacak, mis. sentimen yang berlaku di sekitar partai politik. Dalam konteks yang lebih umum, topik mungkin tidak diketahui secara a priori, dan harus ditemukan terlebih dahulu. Bahkan ketika topik di mana data akan dikumpulkan, seperti situasi krisis, sudah diketahui, metode ini dapat membantu mengidentifikasi kata kunci dan tagar yang sering digunakan untuk membicarakan topik ini. Ketika digunakan sebagai langkah awal, ini dapat membantu peneliti mencapai cakupan topik yang lebih baik daripada yang mungkin dilakukan dengan istilah yang didefinisikan sebagai a priori. Selain itu, penelitian terbaru telah mengidentifikasi tantangan yang biasa ditemui dalam penemuan topik (Chinnov, Kerschke, Meske, Stieglitz, \& Trautmann, 2015). Hal ini menunjukkan bahwa penambahan langkah ini dan inklusi eksplisitnya dalam tinjauan literatur menghasilkan cakupan tantangan yang lebih komprehensif. Ini menghasilkan kerangka kerja empat langkah berikut:

1. Penemuan: "pengungkapan struktur dan pola laten" (Chinnov et al., 2015)

2. Pelacakan: Langkah ini melibatkan keputusan pada sumber data (misalnya Twitter, Facebook), pendekatan, metode, dan output. Subbagian rinci dari langkah ini dapat ditemukan di Stieglitz dkk. (2014). Dalam beberapa penelitian, kelengkapan sumber-sumber Twitter yang berbeda dibandingkan (Driscoll \& Walker, 2014; Morstatter, Pfeffer, \& Liu, 2014; Morstatter, Pfeffer, Liu, \& Carley, 2013).

3. Persiapan: Di luar ini, kerangka kerja awal tidak menjelaskan langkah-langkah persiapan yang diperlukan.

4. Analisis: Bergantung pada tujuan, ada beberapa metode yang tersedia, termasuk analisis jejaring sosial dan penambangan opini. Data yang sudah dikumpulkan kemudian dianalisis secara kuantitatif dan kualitatif. Analisis deskriptif dilakukan guna untuk memberikan gambaran tentang pelaku UMKM yang menjadi subjek penelitian. Data disktiptif dianalisis dengan menggunakan software Microsoft Excel sementara analisis jaringan menggunakan software Gephi ver. 8.0.

\section{Hasil Analisis SNA}

Berikut ini hasil analsa SNA dari jaringan grup BJB Kepri yang menggunakan media sosial Facebook. Dari hasil analsis diperoleh diameter jaringan sebesar 6 unit dan radius sebesar 3 unit. Berikut ini ulasan analisis dalam bentuk ulasan jaringan, ulasan simpul dan ulasan tautan. Untuk ulasan jaringan dilihat dari parameter: degree, average path length, graph density dan modularity, sedangkan ulasan simpul dilihat dari Average Clustering Coefficient, Eigenvector Centrality, Betweenness Centrality, dan Closeness Centrality. Sedangkan ulasan tautan menghitung Average Path Length. 


\section{Ulasan Jaringan}

a) Degree

Derajat simpul adalah jumlah sisi yang berdekatan dengan simpul. Sedangkan Degree Power Law mengukur seberapa dekat distribusi derajat suatu jaringan mengikuti skala kekuatan hukum. Dimana nilai alpha antara 2 dan 3 menyiratkan hukum kekuatan. Hasil perhitungan oleh Gephi mendapatkan Average Degree: 2.200 .

b) Average Path Length

Average Path Length adalah jarak grafik rata-rata antara semua pasangan node. Node yang terhubung memiliki jarak grafik 1. Diameternya adalah jarak grafik terpanjang antara dua node dalam jaringan. (Seberapa jauh terpisah dua node yang paling jauh). Dua ukuran berasal dari jarak: Betweenness Centrality dan Closeness Centrality. Hasil perhitungan oleh Gephi mendapatkan Average Path length sebesar 3.762800071790039.

c) Graph Density

Kepadatan grafis (graph density) mengukur seberapa dekat jaringan untuk diselesaikan. Grafik lengkap memiliki semua tepi dan kerapatan yang mungkin sama dengan 1. Hasil analisis SNA mendapatkan untuk kasus ini Graph Density sebesar: 0.001

d) Modularity ${ }^{2}$

Modularity mengukur seberapa baik jaringan terurai menjadi komunitas modular. Skor modularitas yang tinggi menunjukkan struktur internal yang canggih. Struktur ini, sering disebut struktur komunitas, menggambarkan bagaimana jaringan dibagi menjadi subjaringan. Sub-jaringan (atau komunitas) ini

${ }^{1}$ Ulrik Brandes, A Faster Algorithm for Betweenness Centrality, in Journal of Mathematical Sociology 25(2):163-177, (2001)

\footnotetext{
${ }^{2}$ Vincent D Blondel, Jean-Loup Guillaume, Renaud Lambiotte, Etienne Lefebvre, Fast unfolding of communities in large networks, in Journal of
}

telah terbukti memiliki makna dunia nyata yang signifikan. Pengacakan algoritma dapat menghasilkan dekomposisi yang lebih baik menghasilkan skor modularitas yang lebih tinggi, namun pengacakan akan meningkatkan waktu komputasi. Dalam analisis ini parameter penghitungan modularity menggunakan pengaturan sebagai berikut: Randomize: On; Use edge weights: On; dan Resolution: 1.0. Sedangkan hasil perhitungannya adalah sebagai berikut:

- $\quad$ Modularity $=0.722$

- $\quad$ Modularity with resolution $=0.722$

- $\quad$ Number of Communities $=7$

Secara grafik ${ }^{3}$ dapat dilihat pada Gambar 1. Berikut ini

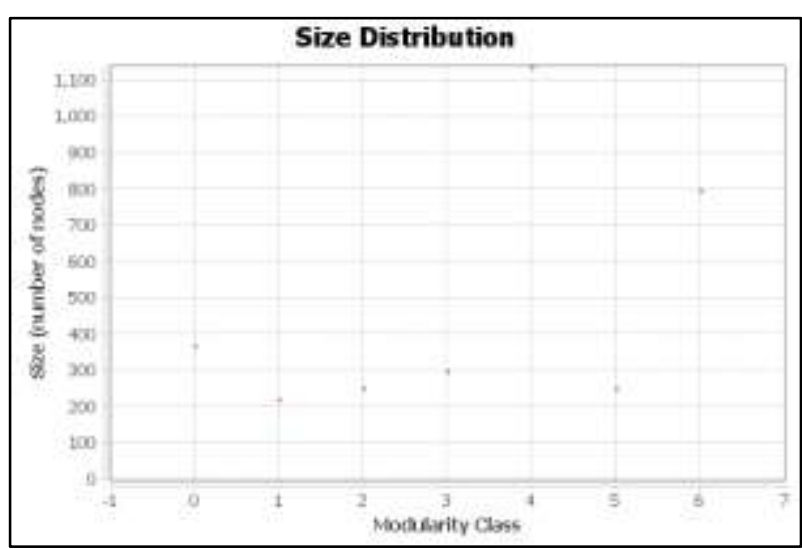

Gambar 1. Grafik Sebaran Degree Distribution

e) PageRank ${ }^{4}$

Pagerank adalah algoritma iteratif yang mengukur pentingnya setiap node dalam jaringan. Metrik menetapkan setiap node probabilitas yang merupakan probabilitas berada di halaman tersebut setelah banyak klik. Nilai peringkat halaman adalah nilai dalam vektor eigen yang memiliki nilai eigen yang paling tinggi dari matriks

3 R. Lambiotte, J.-C. Delvenne, M. Barahona, Laplacian Dynamics and Multiscale Modular Structure in Networks 2009

4 Sergey Brin, Lawrence Page, The Anatomy of a Large-Scale Hypertextual Web Search Engine, in Proceedings of the seventh International Conference on the World Wide Web (WWW1998):107-117 
adjacency yang dinormalkan A '. Matrik adjacency standar dinormalisasi sehingga kolom dari jumlah matriks menjadi 1 . Hasil perhitungan Pagerank adalah sebagai berikut:

- $\quad$ Epsilon $=0.001$

- $\quad$ Probability $=0.85$

Secara Grafik sebaran Page Rank dapat ditampilkan pada Gambar 2 berikut.

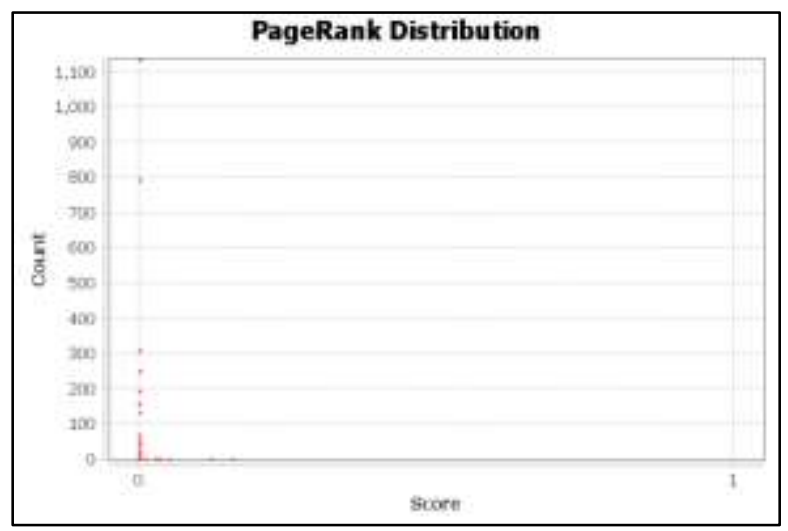

Gambar 2. Grafik Sebaran PageRank

\section{f) Connected Components}

Parameter ini digunakan untuk menentukan jumlah komponen yang terhubung dalam jaringan. Pada grafik directed: ia mendeteksi komponen yang tersambung dengan kuat dan lemah. Pada grafik undirected: ia hanya mendeteksi komponen yang terhubung secara lemah. Dalam teori grafik, komponen yang terhubung (atau hanya komponen) dari graf yang tidak terarah adalah subgraph di mana dua simpul terhubung satu sama lain dengan jalur, dan yang terhubung tidak ada simpul tambahan dalam supergraph. Sebagai contoh, grafik yang ditunjukkan dalam ilustrasi memiliki tiga komponen yang terhubung. Sebuah titik tanpa ujung insiden itu sendiri merupakan komponen yang terhubung. Grafik yang terhubung sendiri memiliki tepat satu komponen terhubung, yang terdiri dari seluruh grafik. Dalam analisis ini Parameter yang digunakan adalah Network Interpretation: undirected. Sedangkan hasil perhitungan

\section{Number of Weakly Connected Components} adalah $=1$

\section{Ulasan Simpul (Node overview)}

a) Average Clustering Coefficient ${ }^{5}$

Koefisien pengelompokan (Watts-Strogatz), ketika diterapkan ke node tunggal, adalah ukuran seberapa lengkap lingkungan dari sebuah node. Ketika diterapkan ke seluruh jaringan, itu adalah koefisien pengelompokan rata-rata atas semua node dalam jaringan.

Tujuan dari analsis ini adalah: Koefisien pengelompokan, bersama dengan jalur terpendek yang berarti, dapat menunjukkan efek "dunia kecil". Untuk koefisien pengelompokan menjadi berarti itu harus secara signifikan lebih tinggi daripada dalam versi jaringan di mana semua tepi telah dikocok.Ling kungan dari node, $\mathrm{u}$, adalah himpunan node yang terhubung ke-u.

Jika setiap node di lingkungan Anda terhubung ke setiap node lain di lingkungan Anda, maka lingkungan Anda lengkap dan akan memiliki koefisien pengelompokan dari 1. Jika tidak ada simpul di lingkungan Anda terhubung, maka pengelompokan koefisien akan menjadi 0. Berikut laporannya:

- Network Interpretation: undirected

- Average Clustering Coefficient $=0.000$

- Total triangles $=0$

b) Eigenvector Centrality

Eigenvector Centrality adalah ukuran penting node dalam jaringan berdasarkan koneksi node. Dalam teori grafik, eigenvector centrality (juga disebut eigencentrality) adalah ukuran pengaruh suatu simpul dalam suatu jaringan. Skor relatif ditugaskan untuk semua node dalam jaringan berdasarkan pada konsep bahwa koneksi ke node dengan nilai tinggi berkontribusi lebih banyak terhadap skor

5 Matthieu Latapy, Main-memory Triangle Computations for Very Large (Sparse (Power-Law)) Graphs, in Theoretical Computer Science (TCS) 407 (1-3), pages 458-473, 2008 
node yang dipertanyakan daripada koneksi yang sama ke node dengan nilai rendah. Skor eigenvector yang tinggi berarti bahwa sebuah node terhubung ke banyak node yang memiliki nilai yang tinggi. Hasil analsisnya adalah sebagai berikut:

- Parameters: Network Interpretation: undirected

- $\quad$ Number of iterations $=100$

- $\quad$ Sum change $=0.06140045120008484$

Secara Grafik sebaran Eigenvector Centrality dapat ditampilkan pada Gambar 3 sebagai berikut.

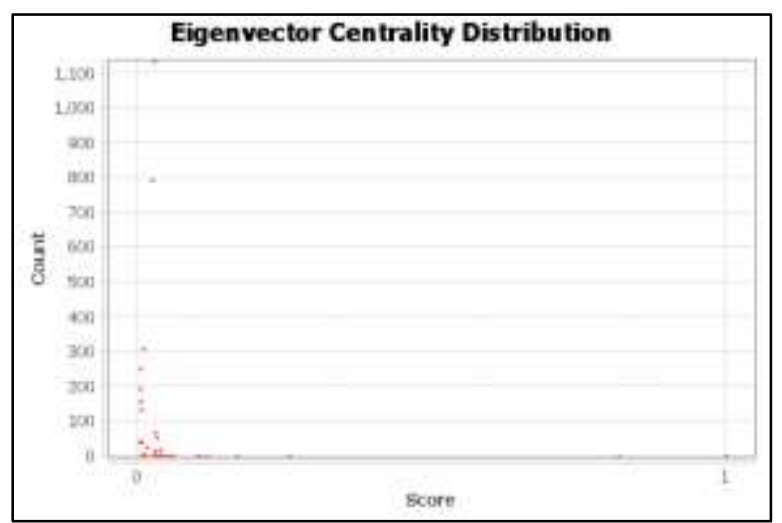

Gambar 3. Grafik Sebaran Eigenvector Centrality

\section{c) Betweenness Centrality}

Betweenness Centrality suatu Node mengukur seberapa sering sebuah node muncul di jalur terpendek antara node dalam jaringan. Dalam teori graph, betweenness centrality adalah ukuran sentralitas dalam grafik berdasarkan jalur terpendek. Untuk setiap pasang simpul dalam grafik yang terhubung, terdapat setidaknya satu jalur terpendek di antara simpul-simpul sedemikian rupa sehingga baik jumlah sisi yang dilalui oleh jalur (untuk grafik yang tidak diberi bobot) atau penjumlahan bobot dari tepi (untuk grafik berbobot). ) diminimalkan. Sentralitas betweenness untuk tiap vertex adalah jumlah jalur terpendek yang melewati verteks.

Betweenness centrality digunakan secara luas dalam teori jaringan: ia mewakili tingkatan dimana node berdiri di antara satu sama lain. Misalnya, dalam jaringan telekomunikasi, node dengan Betweenness centrality yang lebih tinggi akan memiliki kontrol lebih besar atas jaringan, karena lebih banyak informasi akan melewati node tersebut. Betweenness centrality telah digunakan sebagai ukuran umum sentralitas: ia digunakan dalam beragam masalah dalam teori jaringan, termasuk masalah yang terkait dengan jaringan sosial, biologi, transportasi dan kerja sama ilmiah. Secara Grafik sebaran Betweenness Centrality dapat dilihat pada Gambar 4 berikut ini.

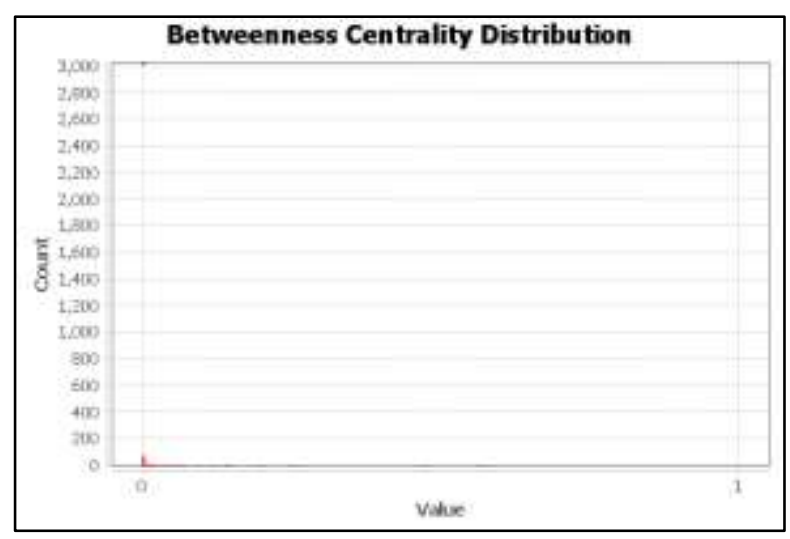

Gambar 4. Grafik Sebaran Betweenness Centrality 
d) Closeness Centrality Closeness Centrality adalah jarak rata-rata dari node yang diberikan ke semua node lain dalam jaringan.

Dalam grafik yang terhubung, closeness centrality dari sebuah node adalah ukuran sentralitas dalam jaringan, dihitung sebagai kebalikan dari jumlah panjang jalur terpendek antara node dan semua node lain

\section{Gambar 5. Grafik Sebaran Closeness Centrality}

Sebagai rangkuman dari analsis simpul, Tabel 1. berikut ini memperlihatkan nilai dari analisa SNA terhadap simpul masing-masing simpul (node) BJB yang diteliti.

Tabel 1. Analisis Simpul untuk jaringan BJB di Kepri

\begin{tabular}{|c|c|c|c|c|c|c|c|}
\hline Id & Label & $\begin{array}{c}\text { closness } \\
\text { centrality }\end{array}$ & $\begin{array}{c}\text { harmonic } \\
\text { closness } \\
\text { centrality }\end{array}$ & $\begin{array}{c}\text { betweeness } \\
\text { centrality }\end{array}$ & pageranks & Degree & $\begin{array}{c}\text { Eigen } \\
\text { centrality }\end{array}$ \\
\hline 1 & FJB-KARIMUN & 0.345 & 0.408 & $1,097,076$ & 0.050 & 424 & 0.258 \\
\hline 3 & JB-NATUNA & 0.350 & 0.380 & $1,379,576$ & 0.029 & 232 & 0.106 \\
\hline 4 & BJB-ANAMBAS & 0.220 & 0.270 & 806,274 & 0.035 & 253 & 0.101 \\
\hline 5 & FJB-DABOSINGKEP & 0.333 & 0.372 & 635,943 & 0.028 & 244 & 0.119 \\
\hline 6 & FJB-BATAM & 0.407 & 0.554 & $3,135,297$ & 0.157 & 1,148 & 1.000 \\
\hline 7 & FJB-UBAN & 0.334 & 0.376 & 520,523 & 0.029 & 263 & 0.168 \\
\hline 8 & FJB-DAIKLINGGA & 0.324 & 0.344 & 199,745 & 0.011 & 102 & 0.048 \\
\hline 9 & BJB-TPIBINTAN & 0.392 & 0.523 & $2,621,674$ & 0.121 & 993 & 0.817 \\
\hline
\end{tabular}

dalam grafik. Dengan demikian, semakin pusat sebuah node, semakin dekat ke semua node lainnya. Secara Grafik sebaran Closeness Centrality dapat dilihat pada Gambar 5 berikut ini.

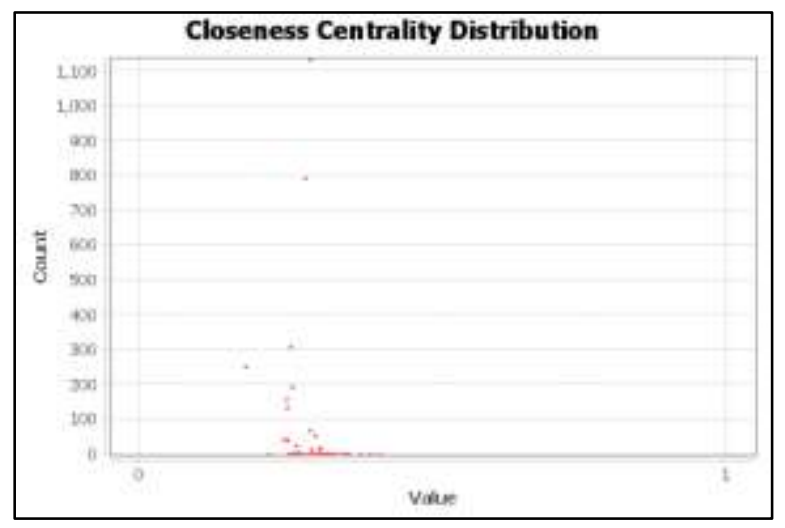

\section{Ulasan Tautan (Edge overview)}

Sebagai rangkuman tautan secara keseluruhan dapat diperlihatkan dari hasil perhitungan panjang rata-rata jalur (average path length) dimana diameter jalur adalah sebesar 6 unit dengan radius sebesar 3 unit, denga nilai ratarata panjang jalur adalah sebesar 3.76. Hasil perhitungan dapat dirangkum sebagai berikut:

- Average Path Length

- Diameter: 6

- Radius: 3

- $\quad$ Average Path length: 3.7628

IV. 
Jurnal Bahtera Inovasi Vol. 3 No. 1 Tahun 2019

Preview Grafik jaringan

Bentuk jaringan BJB melalui media sosial Facebook di Kepri dapat dilihat pada Gambar 6. berikut.

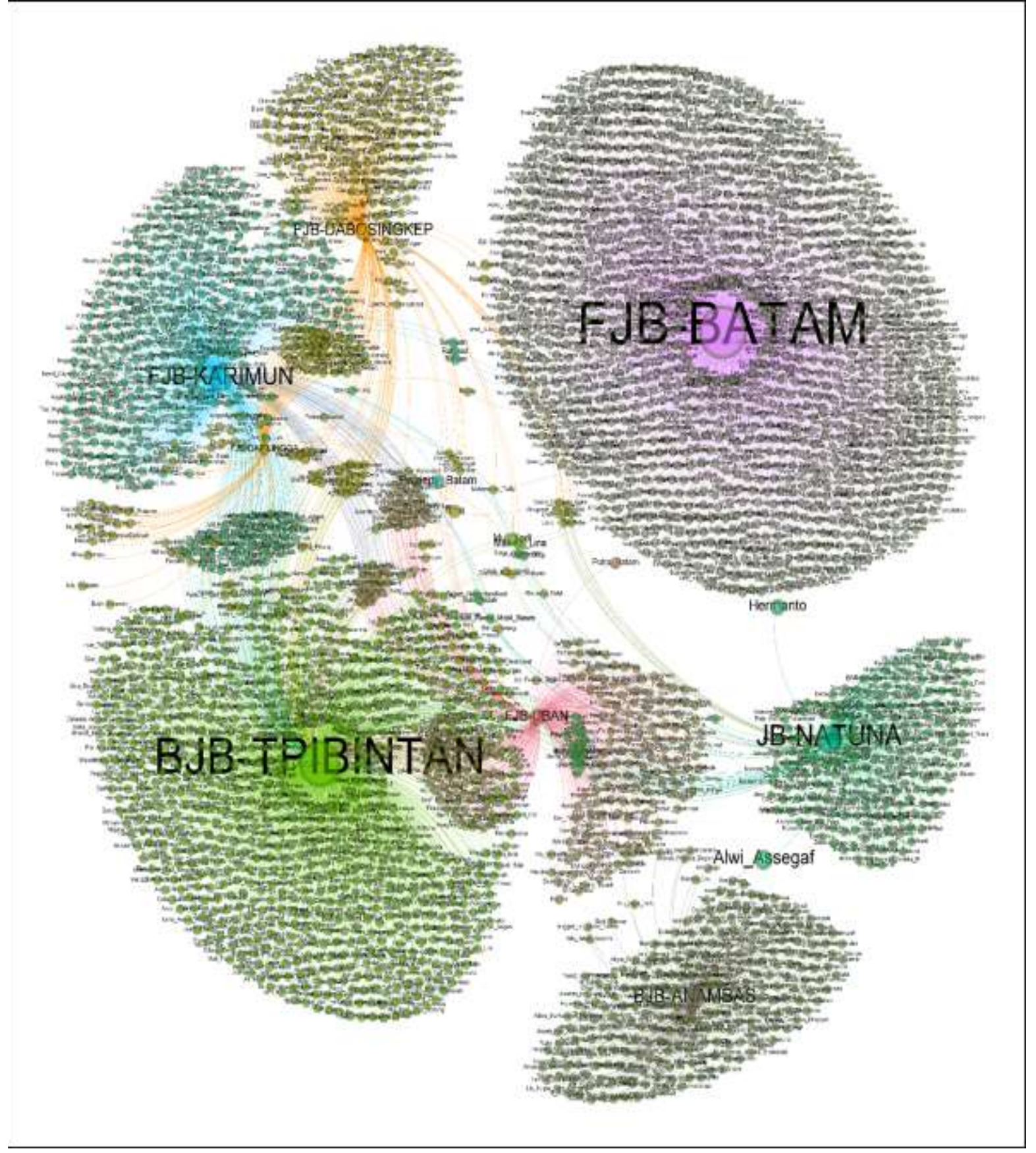

Gambar 6. Grafik Jaringan Facebook BJB di Kepri

\section{Kesimpulan}

Berdasarkan pembahasan di atas maka dapat disimpulkan bahwa:

1. Bentuk pola jaringan marketing dan jual-beli online (e-commerce) oleh UMKM yang terdapat di provinsi Kepulauan Riau masih terpusat pada kota dan kabupaten yang sudah sebih dulu berkembang dan memiliki akses yang lebih baik untuk melakukan jual-beli online. Baik dalam arti fasilitas mauapun letak geografis dan tingkatan ekonominya; 
2. Karakteristik jaringan jual-beli online di kepri masih bersifat kedaerahan. Artinya jaringan masih terkumpul pada kota dan kabupaten bersangkutan. Walaupun dijumpai beberapa node juga memiliki jaingan lebih dari satu BJB.

3. Hubungan antar BJB di kepri masih bersifat sentral, dan belum menyebar.

4. Faktor-faktor yang mendukung berkembangnya pemasaran online di kepri adalah fasilitas internet yang baik dan adanya standarisasi produk..

Saran kami bagi pemerintah daerah adalah agar lebih meningkatkan fasilitas jaringan online dan mensosialisasi dan meningkatkan pengetahuan para penggiat UMKM untuk lebih focus pada pemasaran online. Tentu ini memerluka dukungan dari pihak pemerintah daerah masing-masing.

\section{Daftar Pustaka (APA $6^{\text {th }}$ Style, Mendeley dsj)}

Charu C. Aggarwal (2011), An Introduction to Social Network Data Analytics, in "Social Network Data Analytics, ed. Charu C. Aggarwal," Springer Science+Business Media, Hal. 1-15.

D'Andrea, Alessia; et al. (2009). An Overview of Methods for Virtual Social Network Analysis. In "Abraham, Ajith. Computational Social Network Analysis: Trends, Tools and Research Advances." Springer. Hal. 8.

Ding, Julian (1999), E-commerce: Law \& Practice, Sweet \& Maxwell Asia, 1999 . Business \& Economics - Hal. 416.

Grandjean, Martin (2016). A social network analysis of Twitter: Mapping the digital humanities community. Cogent Arts \& Humanities. Vol.3, No. 1.

Grandjean, Martin (2017). Analisi e visualizzazioni delle reti in storia. L'esempio della cooperazione intellettuale della Società delle Nazioni. Memoria e Ricerca No.2, Hal. 371-393.

Koochakzadeh, N., Sarraf, A., Kianmehr, K., Rokne, J., dan Alhajj, R. (2011). NetDriller: A Powerful Social Network Analysis Tool.
"2011 IEEE $11^{\text {th }}$ International Conference on Data Mining Workshops," Hal. 1235-1238. Nor Amalina Abdul Rahim dan Sarina Sulaiman, (2015), Social Network Analysis for Political Blogosphere dataset, International Journal of Advance Software Computer Application, Vol. 7, No. 3, November 2015.

Otte, Evelien dan Rousseau, Ronald (2002). Social network analysis: a powerful strategy, also for the information sciences. Journal of Information Science. Vol. 28, No.6, Hal. 441-453.

Palazuelos, C., Garc, D., dan Zorrilla, M. (2013). Social Network Analysis and Data Mining : An Application to the E-Learning Context, Hal. 651-660.

Pinheiro, Carlos A.R. (2011). "Social Network Analysis in Telecommunications." John Wiley \& Sons. Hal. 4.

Priambada, Swasta (2015), Manfaat penggunaan media sosial pada usaha kecil Menengah (UKM), "Seminar Nasional Sistem Informasi Indonesia," 2-3 November 2015, Program Studi Administrasi Bisnis, Fakultas Ilmu Administrasi, Universitas Brawijaya. hal. 41-46.

Öztamur, Dilhan., dan İbrahim Sarper Karakadilar, (2014), Exploring the role of social media for SMEs: as a new marketing strategy tool for the firm performance perspective, Procedia-Social and Behavioral Sciences, 150 (2014), hal. 511 - 520.

Septyato, Dihin dan Ignatius Joko Dewanto (2016) Pengembangan strategi e-marketing UMKM di Indonesia, " Prosiding Seminar Nasional: Dinamika Global : Rebranding Keunggulan Kompetitif Berbasis Kearifan Lokal," Fakultas Ekonomi Universitas Esa Unggul, Magister Teknik Informatika STMIK Raharja. hal. 165-172.

Setiawati, Ira dan Penta Widyartati, (2017) Pengaruh strategi pemasaran online terhadap peningkatan laba UMKM, "Seminar Nasional dan Call for Paper 2017 Strategi Pengembangan Sumber Daya Manusia Melalui Publikasi Jurnal Ilmiah 
dalam Menyikapi Permenristekdikti RI No.20 Tahun 2017" hal. 343-347.

Supriyati, Endang dan Mohammad Iqbal (2013),

Faktor adopsi internet marketing untuk usaha mikro dan usaha kecil Menengah (UMKM) di Kabupaten Kudus dengan SEM (Structural Equation Model) dan Framework Cobit 4.1, Jurnal SIMETRIS, Vol 3 No 1 April 2013, hal. 1-6.

Stieglitz, Stefan., Milad Mirbabaie, Björn Ross, dan Christoph Neuberger (2018), Social media analytics - Challenges in topic discovery, data collection, and data preparation, International Journal of Information Management, No.39 (2018), hal. 156-168
Zeng, W., Huang, Y., dan Jiang, L. (2011). The study of microblog marketing based on social network analysis. Proceedings - 2011 4th International Conference on Information Management, Innovation Management and Industrial Engineering, ICIII 2011, Vol.3, hal. 410-415.

Zhu, M., Liu, W., Hu, W., dan Fang, Z. (2009). Social Network Analysis in IT Company. 2009 International Conference on $E$ Learning, E-Business, Enterprise Information Systems, and E-Government, hal. 305-307. 